\title{
Longitudinal Analysis of Built Environment and Aerosol Contamination Associated with Isolated COVID-19 Positive Individuals
}

\section{Patrick Horve}

Biology and the Built Environment Center, University of Oregon, Eugene, OR, 97403

\section{Leslie Dietz}

Biology and the Built Environment Center, University of Oregon, Eugene, OR, 97403

\section{Garis Bowles}

Biology and the Built Environment Center, University of Oregon, Eugene, OR, 97403

\section{Georgia MacCrone}

Biology and the Built Environment Center, University of Oregon, Eugene, OR, 97403

\section{Andreas Olsen-Martinez}

Biology and the Built Environment Center, University of Oregon, Eugene, OR, 97403

\section{Dale Northcutt}

Energy Studies in Buildings Laboratory, University of Oregon, Eugene, OR, 97403

\section{Vincent Moore}

Biology and the Built Environment Center, University of Oregon, Eugene, OR, 97403

\section{Liliana Barnatan}

Biology and the Built Environment Center, University of Oregon, Eugene, OR, 97403

\section{Hooman Parhizkar}

Energy Studies in Buildings Laboratory, University of Oregon, Eugene, OR, 97403

Kevin Van Den Wymelenberg ( $\sim$ kevinvdw@uoregon.edu )

Institute for Health and the Built Environment, University of Oregon, Portland, OR, 97209

\section{Research Article}

Keywords: COVID-19, SARS-CoV-2, aerosol, viral load

Posted Date: August 31st, 2021

DOI: https://doi.org/10.21203/rs.3.rs-861942/v1

License: (c) (1) This work is licensed under a Creative Commons Attribution 4.0 International License.

Read Full License 
9

Title: Longitudinal Analysis of Built Environment and Aerosol Contamination Associated with Isolated COVID-19 Positive Individuals

Funding Statement: Funding for this research was partially provided by Thermo Fisher Scientific under award number 4133V1, as well as a confidential gift to the University of Oregon. 


\section{Abstract}

The indoor environment is the primary location for the transmission of severe acute respiratory

22

23

24

25

26

27

28

29

30

31

32

33

34

35

36

37

3
syndrome coronavirus 2 (SARS-CoV-2), the causative agent of coronavirus disease 2019 (COVID19), largely driven by respiratory particle accumulation in the air and increased connectivity between the individuals occupying indoor spaces. In this study, we aimed to track a cohort of subjects as they occupied a COVID-19 isolation dormitory to better understand the impact of subject and environmental viral load over time, symptoms, and room ventilation on the detectable viral load within a single room. We find that subject samples demonstrate a decrease in overall viral load over time, symptoms significantly impact environmental viral load, and we provide the first real-world evidence for decreased aerosol SARS-CoV-2 load with increasing ventilation, both from mechanical and window sources. These results may guide environmental viral surveillance strategies and be used to better control the spread of SARS-CoV-2 within built environments and better protect those caring for individuals with COVID-19. 


\section{Introduction}

The built environment $(\mathrm{BE})_{1,2}$, or the spaces that we, as humans, have built for ourselves to work in, inhabit, and enjoy life, play an essential role in mitigating the spread of severe acute respiratory syndrome coronavirus 2 (SARS-CoV-2), the causative agent of coronavirus disease 2019 (COVID19)3. SARS-CoV-2 transmission indoors is aided through extended close contact and the accumulation and persistence of aerosolized SARS-CoV-2, largely driven by poor ventilation ${ }^{417}$. Significant effort has gone into the identification of SARS-CoV-2 in a multitude of BE'S $6,8,1,1,1,1,1,1,1,2,2,20-32$. However, most efforts to understand the environmental contamination associated with individuals diagnosed with COVID-19 have been performed at a single time point, missing critical information about the longitudinal dynamics of that environmental contamination. Additionally, minimal characterization has been performed to understand how symptoms and BE factors such as ventilation, measured in air changes per hour $(\mathrm{ACH})$, impact the total environmental and aerosolized contamination by SARS-CoV-2 within the BE over time.

One common scenario faced by people throughout the world is co-occupation of an indoor space with a COVID-19 positive individual while they themselves are not known to be positive. Three of the major outstanding questions in regard to COVID-19 infections and the built environment include (i) how individuals emit virus into the environment over time, (ii) how different forms of environmental sampling are able to support biosurveillance initiatives, and (iii) and to what degree does ventilation mitigate environmental contamination. In order to better understand the longitudinal dynamics associated with the occupation of the BE when suffering from COVID-19, the impact of ventilation, and the potential role of different surveillance methods, isolation dorm rooms housing residence hall students that tested positive for COVID-19 were sampled throughout the course of the individual's isolation period, typically allowing for up to 10 days of sample collection. Here, we provide the first real-world experimental evidence for the suppression of 
aerosol viral loads through the use of increased $\mathrm{ACH}$ from exhaust air and increased natural ventilation through the use of windows. Additionally, we demonstrate that symptom type, severity, and presence are predictive factors for the level of environmental contamination observed and that environmental contamination decreases as individuals recover. Additionally, we identified variability in viral shedding over time and provide evidence useful to guide environmental viral surveillance.

\section{Results and Discussion}

\section{Study Population}

A total of 35 subjects were recruited and consented into the study between January and May 2021. All subjects tested positive for SARS-CoV-2 RNA through shallow nasal swabs and qRT-PCR. The study cohort was made up of 17 males and 18 females between the age of 18 and 24 (Table 1). The majority of individuals in the study cohort identified as White (68.6\%) followed by Hispanic/Latino/Spanish (14.3\%). A full breakdown of the self-identifying ethnicity of the study cohort can be found in Table 1.

Table 1. Demographic data of the study subjects.

\begin{tabular}{cc}
\hline Sex at Birth & Percent (n) \\
\hline Male & $48.6(17)$ \\
Female & $51.4(18)$ \\
\hline Ethnicity & Percent (n) \\
\hline White & $68.6(24)$ \\
Hispanic/Latino/Spanish & $14.3(5)$ \\
Native Hawaiian/Pacific Islander & $2.9(1)$ \\
Black & $2.9(1)$ \\
Multiple & $5.7(2)$ \\
Asian & $5.7(2)$ \\
\hline
\end{tabular}


Viral Shedding and Environmental Contamination Associate with Isolation Day

In an attempt to assess the viral load dynamics over the course of the study cohort's time in the isolation dormitory, the mean $\mathrm{C}_{\mathrm{T}}$, a proxy for observed total viral load, of each study participant from each location was tracked throughout the course of the isolation period. $\mathrm{C}_{\mathrm{T}}$ values of subject shallow nasal and mouth swabs were found to be significantly $(P<0.05)$ associated with day since positive test, with $\mathrm{C}_{\mathrm{T}}$ values increasing (lower viral load) as time since positive test increases (Figure 1). Additionally, significant increases in $C_{\mathrm{T}}$ values were observed as time progressed in environmental swabs taken from the study subject's computer, phone, the settling plate closest to the study participant, and in the active air samples (AerosolSense). Statistically significant increases in the $\mathrm{C}_{\mathrm{T}}$ values of participant bathroom floors, bathroom exhaust, and far passive air settling plate were not observed, although nearly all sample types trended towards increased $\mathrm{C}_{\mathrm{T}}$ values over time. Furthermore, environmental samples demonstrated decreasing percent positivity over time (Figure 2).

Increasing nasal and mouth $\mathrm{C}_{\mathrm{T}}$ values and decreasing rate of positivity of environmental samples as the isolation period progresses both suggest that decreasing viral load in study participants directly translates to decreased viral load within the space occupied by individuals positive for COVID-19 Figure 1). While previous investigations have demonstrated the presence of SARS-CoV-2 RNA in BE's occupied by COVID-19 positive individuals ${ }^{5,18,23,32-34}$, this represents the first link between infection stage, subject viral load over time, and environmental viral load. Additionally, we confirm the findings of multiple other studies that have demonstrated the persistence of SARS-CoV-2 genetic material in patient-derived samples at the end of a treatment and/or isolation period ${ }^{35,36}$. The persistence of environmental SARS-CoV-2 genomic material has been cited as a potential limitation in multiple sampling campaigns that utilize surface swabs to assess contamination ${ }^{37,38}$. The strongest trends in increasing $\mathrm{C}_{\mathrm{T}}$ values among environmental samples were observed in the phone and 
101 computer swabs, and AerosolSense active air samples. In comparison to samples that did not 102 demonstrate a significant increase in $C_{T}$ values over time (bathroom exhaust and bathroom floor), 103 these sampling locations were either cleaned in between sampling (phone and computer) or utilize a 104 fresh substrate during each collection period (AerosolSense). This comparison suggests that relic 105 RNA may compose at least a part of the RNA collected in some environmental surveillance 106 sampling methods and that sampling methods that routinely cleaned or were more resistant to relic 107 RNA collection (such as active air sampling with a fresh substrate) may provide more utility as a 108 surveillance tool against SARS-CoV-2 than typical environmental swabbing campaigns. 
Bathroom Floor

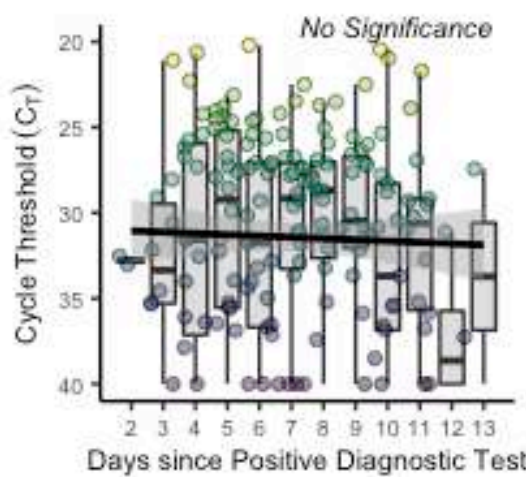

Computer

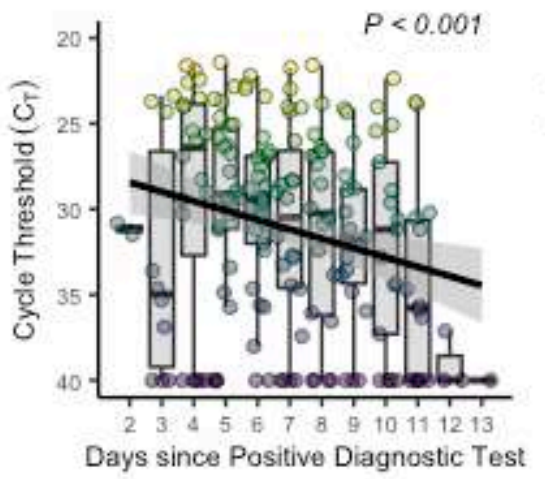

Near Settling Plate

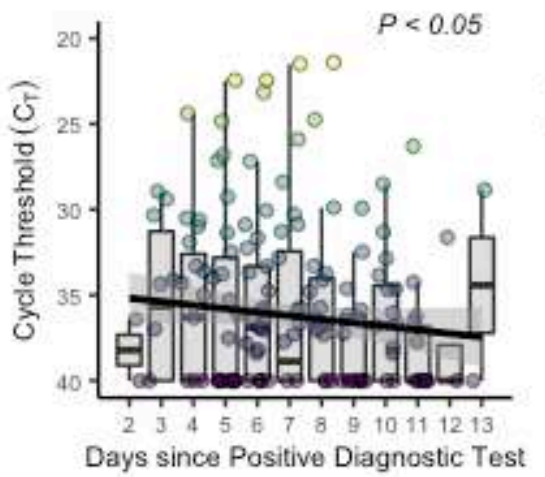

Phone

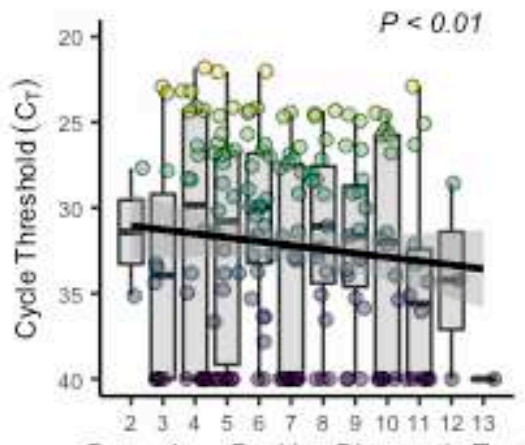

Days since Positive Diagnostic Test

Mouth Swab

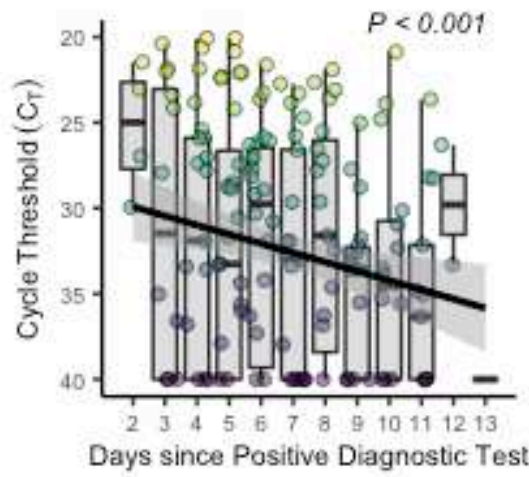

Far Settling Plate

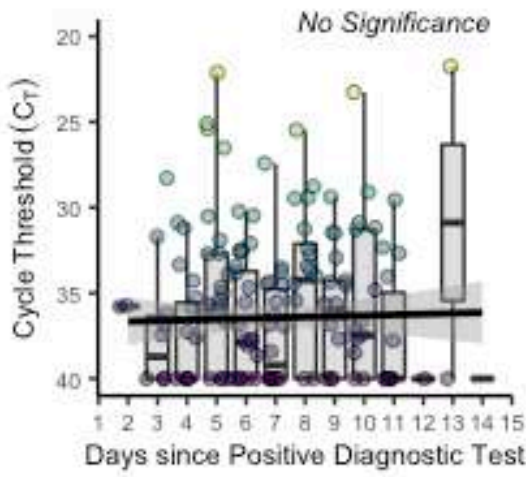

Shallow Nasal Swab

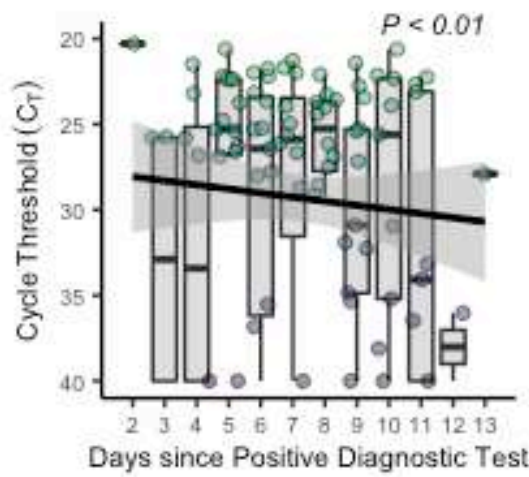

Bathroom Exhaust

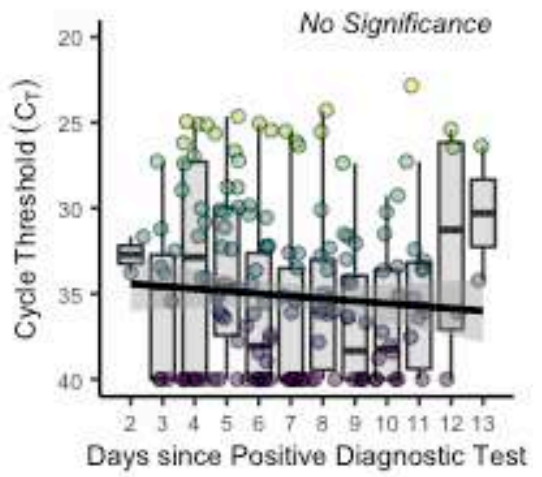

AerosolSense

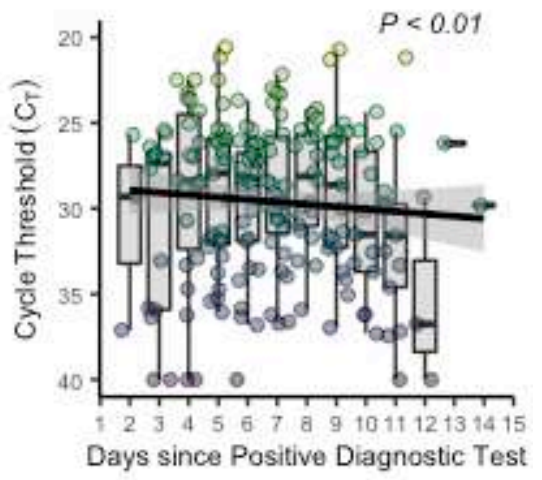

Figure 1. Longitudinal Viral Shedding and Environmental Contamination Dynamics. The mean daily cycle threshold $\left(\mathrm{C}_{T}\right)$ for each sampling location throughout the course of the participants' involvement in the study. Individual points represent the mean daily $\mathrm{C}_{\mathrm{T}}$ value per individual. The black line represents a linear mixed model estimated using a restricted maximum likelihood (REML) approach and including the individual occupying the room as a random effect and the grey area represents the $95 \%$ confidence interval for that model. 
Bathroom Floor

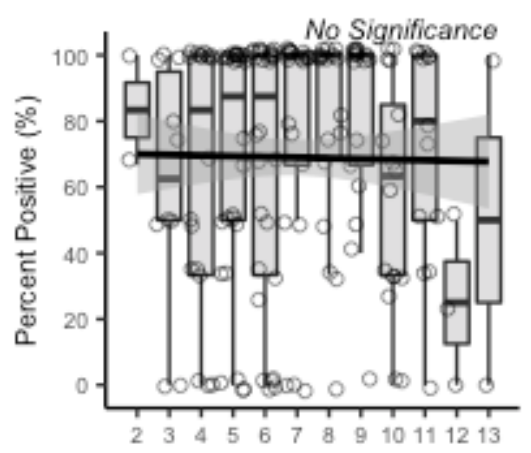

Days since Positive Diagnostic Test

Computer

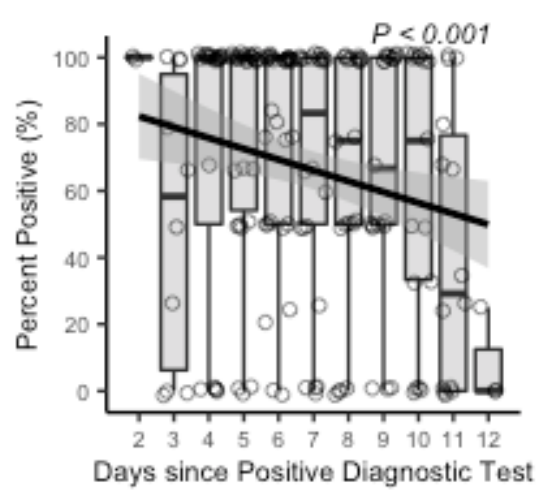

Near Settling Plate

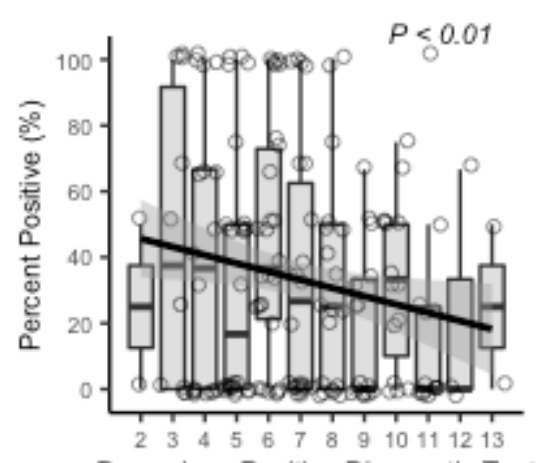

Days since Positive Diagnostic Test
Phone

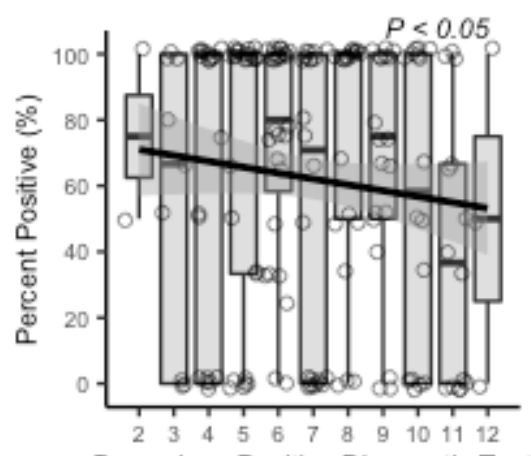

Days since Positive Diagnostic Test

Mouth Swab

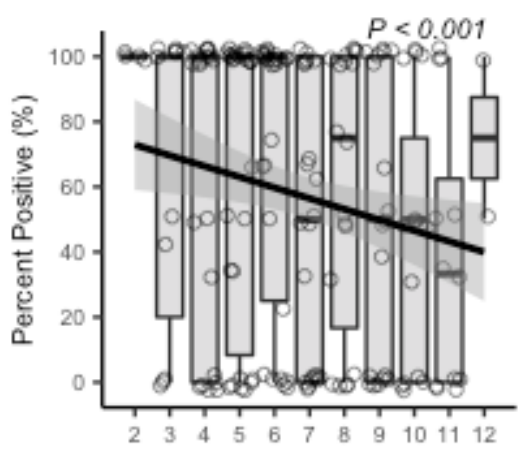

Days since Positive Diagnostic Test

Far Settling Plate

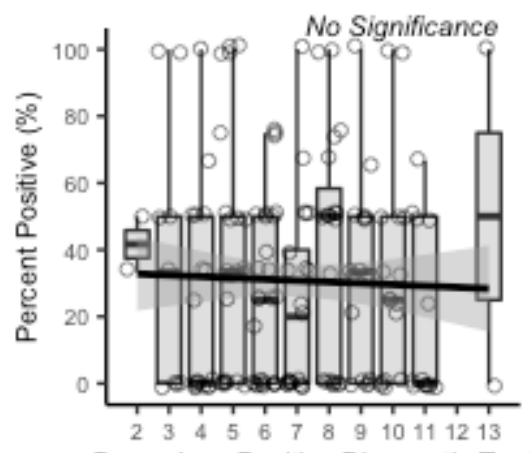

Days since Positive Diagnostic Test

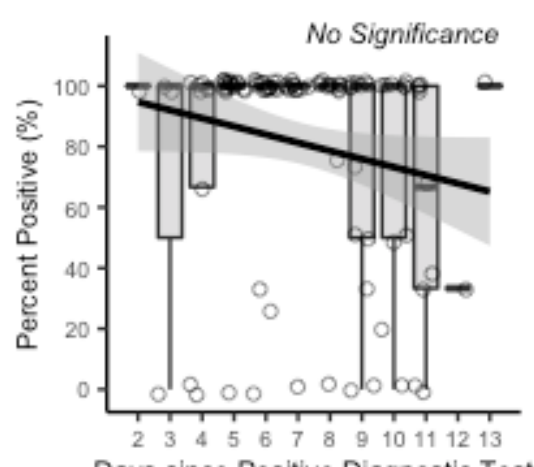

Days since Positive Diagnostic Test

Bathroom Exhaust

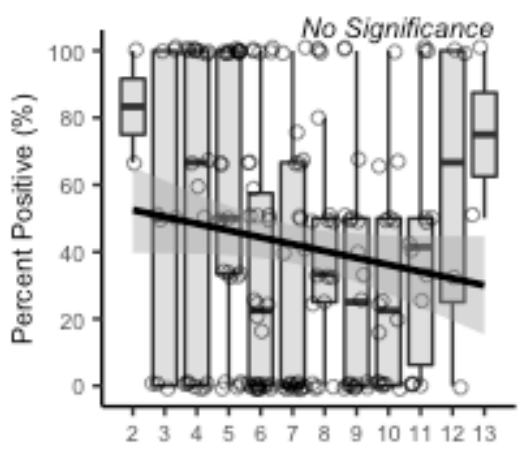

Days since Positive Diagnostic Test

AerosolSense

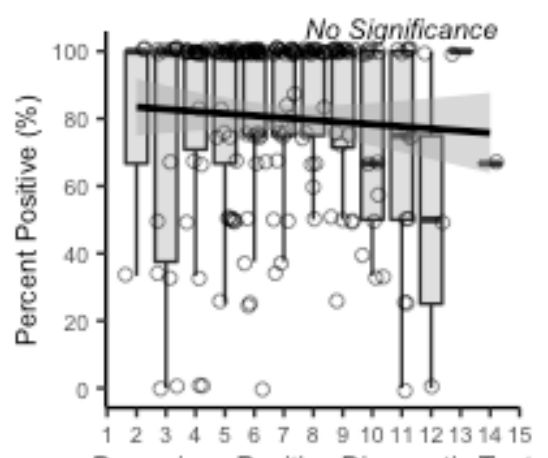

Days since Positive Diagnostic Test

Figure 2. Mean daily percent positivity at each sampling location. The percent positivity rate per entry per study subject was calculated and the mean positivity rate of all participants per day enrolled in the study was calculated as the daily percentage rate. The black line represents a linear mixed model estimated using a restricted maximum likelihood (REML) approach and including the individual occupying the room as a random effect and the grey area represents the $95 \%$ confidence interval for that model.

\section{Symptom Presence Impacts Viral Shedding and Environmental Contamination}

The presence (or lack thereof) of symptoms associated with COVID-19 positive individuals and

associated viral load in patient samples (nasopharyngeal and oral swabs) has been investigated in a 
multitude of previous articles and significant differences have not been identified in the viral load

126 associated with symptomatic versus asymptomatic COVID-19 infections ${ }^{39-47}$. However, the

127

128

129

130

131

132

133

134 relationship between symptomatic infection and environmental contamination has not yet been

investigated. Among the symptoms that were reported by the study population, seven symptoms (coughing, watering eyes, sore throat, loss of smell, gastroinstestinal (GI) symptoms, congestion, and brain fog) were found to be significantly associated with altered levels of viral load in the isolation dormitory rooms (Table 2). Increased self-reported coughing, sore throat, loss of smell, and GI symptoms were associated with lower environmental $\mathrm{C}_{\mathrm{T}}$ values (and thus higher viral loads), with GI symptoms and coughing most strongly correlating with decreased $C_{\mathrm{T}}$ values. In comparison, watery eyes, congestion, and brain fog were associated with increased $\mathrm{C}_{\mathrm{T}}$ values. Coughing while infected with COVID-19 has been estimated to produce significantly more viral particles than normal breathing $^{48}$. This small cohort study of 35 individuals supports the hypothesis that increased respiratory expulsion from activities such as coughing would result in increased environmental contamination with SARS-CoV-2 $2^{49,50}$. Furthermore, it is known, through wastewater analysis and sequencing for the surveillance of SARS-CoV-2 $2^{51}$, that SARS-CoV-2 is readily emitted from and detected in stool samples in nearly half of COVID-19 positive individuals ${ }^{52}$. Here we observe increased viral load associated with increased GI symptoms, further supporting the potential for a fecal-oral transmission route of SARS-CoV-2 in certain circumstances. Additionally, the other symptoms associated with increased environmental viral load (sore throat and loss of smell) both implicate the upper respiratory tract. Active viral replication has been identified in the upper respiratory tract and suggests that ongoing infection and symptom onset in the upper respiratory tract may indicate increased levels of viral secretion and environmental contamination in buildings ${ }^{53}$.

Table 2. Linear correlations between the self-reported symptoms of study participants and measured cycle threshold values in the environmental samples. The statistical significance of the correlation for each symptom is noted, and the slope indicates the direction of the relationship whereas negative values indicate increased environmental viral load. 


\begin{tabular}{|c|c|c|}
\hline \multicolumn{3}{|c|}{ Symptom Correlation Coefficients } \\
\hline Symptom & Slope & Significance Level \\
\hline Fever & -0.35 & Not Significant \\
\hline Coughing & -0.52 & $<0.001$ \\
\hline Sneezing & -0.12 & Not Significant \\
\hline Difficulty Breathing & -0.03 & Not Significant \\
\hline Fatigue & 0.13 & Not Significant \\
\hline Headache & -0.16 & Not Significant \\
\hline Eyes Ache & 0.15 & Not Significant \\
\hline Eyes Watering & 1.48 & $<0.001$ \\
\hline Sore Throat & -0.30 & $<0.05$ \\
\hline Distorted Taste & 0.06 & Not Significant \\
\hline Loss of Taste & 0.01 & Not Significant \\
\hline Distorted Smell & 0.00 & Not Significant \\
\hline Loss of Smell & -0.13 & $<0.01$ \\
\hline Ears Ringing & 0.37 & Not Significant \\
\hline GI Symptoms & -0.93 & $<0.01$ \\
\hline Congestion & 1.00 & $<0.001$ \\
\hline Brain Fog & 0.31 & $<0.01$ \\
\hline
\end{tabular}

151 We sought to further understand the potential impact that symptoms play in the transmission of

152 SARS-CoV-2 inside of the BE, and particularly, the impact symptom presence may have on

153 subsequent environmental contamination. As such, each entry into a study participant's room was

154 queried to determine if the participant had self-reported any symptoms during that visit only.

155 Individual entries were sorted into symptomatic and asymptomatic entries and the $\mathrm{C}_{\mathrm{T}}$ values from

156 each group were compared. Significantly lower $C_{T}$ values were observed in active air samples

157 collected during entries where the participant reported symptoms (Figure 3a), representing greater

158 aerosolized viral particles present during that collection time. Furthermore, significantly lower $C_{T}$ 
values were observed in aerosol-based sampling methods (active air samples and passive settling

160
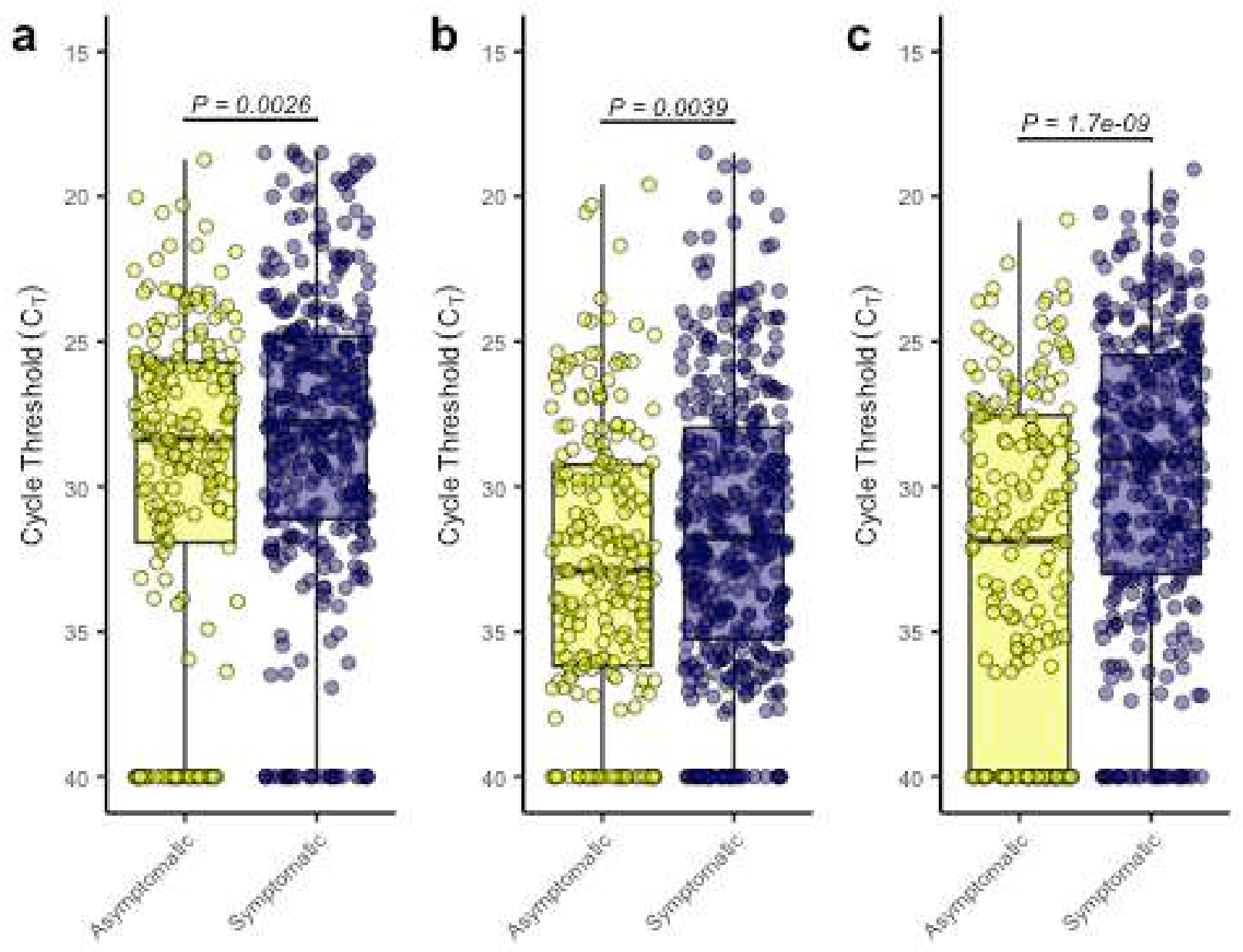

Figure 3. Impact of symptom presence on viral shedding and detection. (a) Boxplots of the observed cycle threshold values for active air samples collected by the AerosolSense sampler from rooms occupied by asymptomatic (yellow) and symptomatic (purple) individuals. (b) Boxplots of observed cycle threshold values for aerosol particulate samples collected by the AerosolSense sampler, passive air settling plate, and bathroom exhaust vents from rooms occupied by asymptomatic (yellow) and symptomatic (purple) individuals. (c) Boxplots of the observed cycle threshold values for environmental swabs collected from the computer, phone, and bathroom floor from rooms occupied by asymptomatic (yellow) and symptomatic (purple) individuals. 
Additionally, some subjects enrolled in the study demonstrated intermittent negative shallow nasal and oral swabs. To understand whether these intermittent periods of potentially low viral source load further translated to decreased levels of aerosolized viral particles, each entry into a study participant's room was investigated to determine whether a positive or negative human swab (shallow nasal and oral swabs separately) was associated with that entry. Significantly lower $\mathrm{C}_{\mathrm{T}}$ values were observed in active air samples collected during entries where the participant returned a positive shallow nasal swab (Figure 4a). This same statistically significant relationship was also observed when grouping samples based upon the result of their oral swabs (Figure 4b). Some intermittent detection of SARS-CoV-2 RNA in the later stages of infection have been previously reported ${ }^{54-56}$. COVID-19 is unique in that it has been associated with significant numbers of super spreader events $^{11,57-59}$. It has been suggested that as low as $2 \%$ of COVID-19 positive individuals may account for up to $20 \%$ of confirmed $\operatorname{cases}^{57}$. Here, we find a potential relationship between intermittent positivity, symptom dynamics, and the detectable viral load of the subject and their environment. We hypothesize that individuals suffering from COVID-19 may undergo transient periods of viral shedding that may contribute (among many other factors) to lack of transmission in some exposure events and super spreader transmission in other exposure events. This potential intermittency of viral shedding underscores the value of high temporal resolution of environmental viral surveillance. 

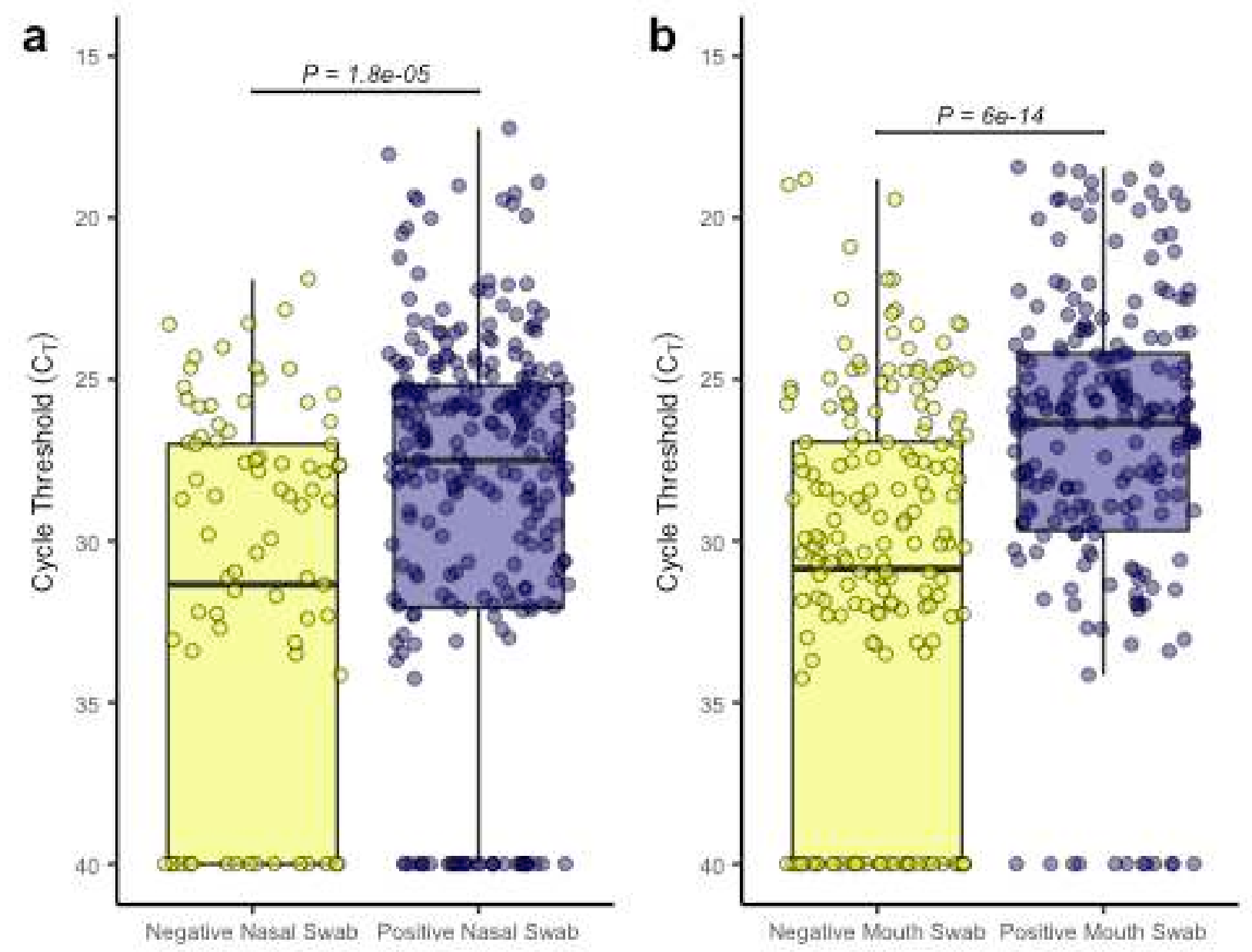

Figure 4. Potential intermittency of viral shedding and production. (a) Boxplots of the observed cycle threshold values for active air samples collected by the AerosolSense sampler from room entries when the study participant returned a negative shallow nasal swab (yellow) and a positive shallow nasal swab (purple). (b) Boxplots of the observed cycle threshold values for active air samples collected by the AerosolSense sampler from room entries when the study participant returned a negative oral swab (yellow) and a positive oral swab (purple).

\section{Built Environment Factors and Environmental Viral Detectivity}

The BE has been demonstrated to be an area of high risk when there is a COVID-19 positive individual occupying the indoor space ${ }^{60-64}$. Despite initial guidance that SARS-CoV-2 is transmitted through droplets and close interactions between individuals ${ }^{65}$, it has become readily apparent that a major transmission method is through aerosolized viral particles that remain suspended in the air for extended periods of time $\mathrm{s}^{5,6-10,14-17}$. As such, we sought to understand the relationship between a range of air exchange rates in the isolation rooms studied and detectability of aerosolized SARS- 
$\mathrm{CoV}-2$. The rate of exhausted air was measured from each isolation dorm room and the air changes

205 per hour (ACH) were calculated for each room (See Materials and Methods for full details). The

206 ACH from mechanically exhausted air in the isolation dorm rooms ranged from $0.16 \mathrm{ACH}$ to 0.93

207 ACH (Figure 5a). Current American Society of Heating, Refrigerating, and Air-Conditioning

208 Engineers (ASHRAE) guidelines suggest a minimum of $0.35 \mathrm{ACH}$ for multifamily units, $1.7 \mathrm{ACH}$

209 for retail spaces, and 2.8 ACH for classrooms ${ }^{66}$. ACH from mechanical exhaust in the isolation

210 rooms was found to be significantly and positively related to observed $\mathrm{C}_{\mathrm{T}}$ values $(P<0.01)$, with

211 increased $\mathrm{ACH}$ in the room more likely to produce higher $\mathrm{C}_{\mathrm{T}}$ values, thus lower viral loads (Figure

212 5b). However, a significant decrease in the percent positivity of aerosol samples was not observed $(P$

$213=0.43)$ as ACH increased across study rooms (Figure 5c).. Taken together, these results suggest that,

214 even across a fairly narrow and low range of $\mathrm{ACH}$, increased ventilation rate decreases the

215 detectable aerosolized viral load within enclosed spaces. However, the lack of significance in the

216 decrease in percent positivity suggests that the modest range of $\mathrm{ACH}$ values found in this study is

217 not enough to decrease the abundance of viral particles in the enclosed space to an undetectable

218 level, thus suggesting higher $\mathrm{ACH}$ is required to support safer indoor congregation. Multiple articles

219 have previously hypothesized that increased ventilation rate would translate to lower airborne viral

$220 \operatorname{loads}^{22,67-70}$. To our knowledge, this study demonstrates the first real-world experimental evidence of

221 increased ventilation within the built environment contributing to decreased aerosolized viral load.

222 One common method for increasing the ventilation that is available in the vast majority of BE's is the operation of windows. Windows can dramatically increase the overall ACH within buildings and other enclosed spaces ${ }^{71}$. In this case, opening a dorm room window will decrease the pressure on the

225 mechanical ventilation (the exhaust air fan in the bathroom) and increase the efficiency of air

226 movement by the exhaust fan ${ }^{72}$. More importantly, opening a window often increases the absolute

$227 \mathrm{ACH}$ (not just the measured $\mathrm{ACH}$ of the mechanical exhaust, in the room through increased air 
movement in and out of the open window ${ }^{73}$. In order to assess the potential impact of window

229 operations on the aerosolized viral load present within the study participant's rooms, study

230 participants were asked the status of their room windows during the course of the previous sampling

231 period and researchers observed current window operation status at each entry. Samples were split

232 into two groups consisting of (i) the window was open for more than $50 \%$ of the sampling period or

233 (ii) the window was open for less than $50 \%$ of the sampling period. Samples from aerosol collection

234 methods (AerosolSense and passive settling plates) demonstrated a significant increase in $\mathrm{C}_{\mathrm{T}}$ values

235 (correlating with a decrease in viral load) when the window was open for more than $50 \%$ of the

236 sampling period (Figure 5d). These results suggest that the increased ventilation that is provided

237 from an open window has the ability to reduce the detectable viral load in the room by half (or

238 more) when windows are open $\left(\mathrm{x}^{-}=34.4\right)$ compared to when the windows are closed $\left(\mathrm{x}^{-}=33.2\right)$.

239 Window opening, as suggested by a variety of previous analyses and reviews ${ }^{69,74-78}$, appears to

240 provide significant reduction in viral load while being a low-cost and low-labor intervention when

241 thermal control, security, and outdoor contaminants are not a concern. 


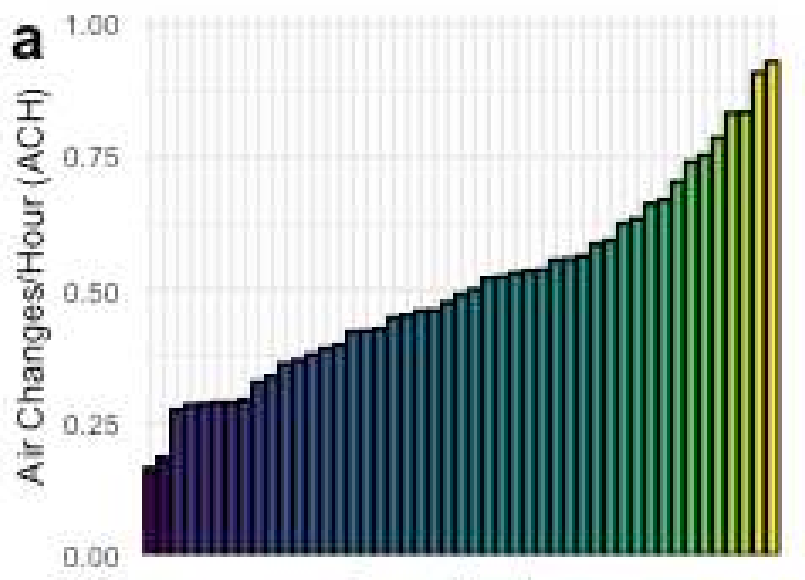

Room Number

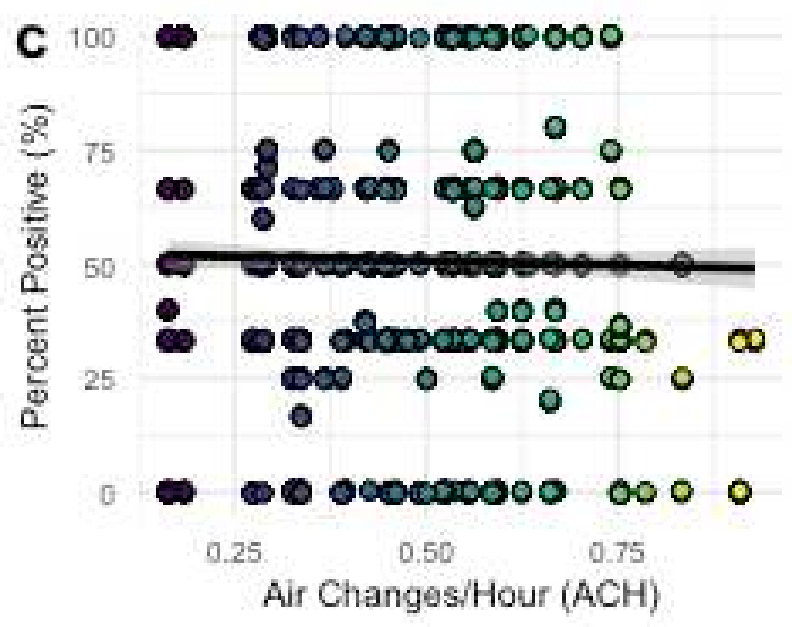

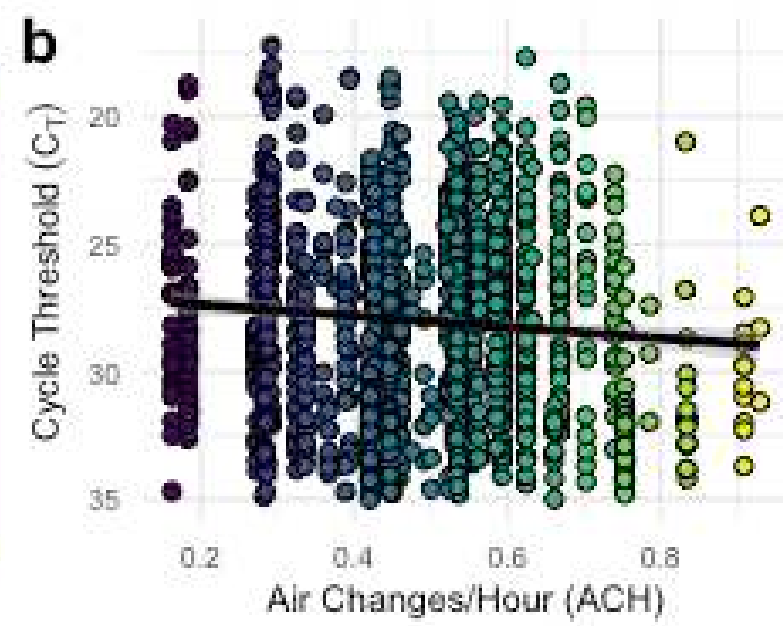

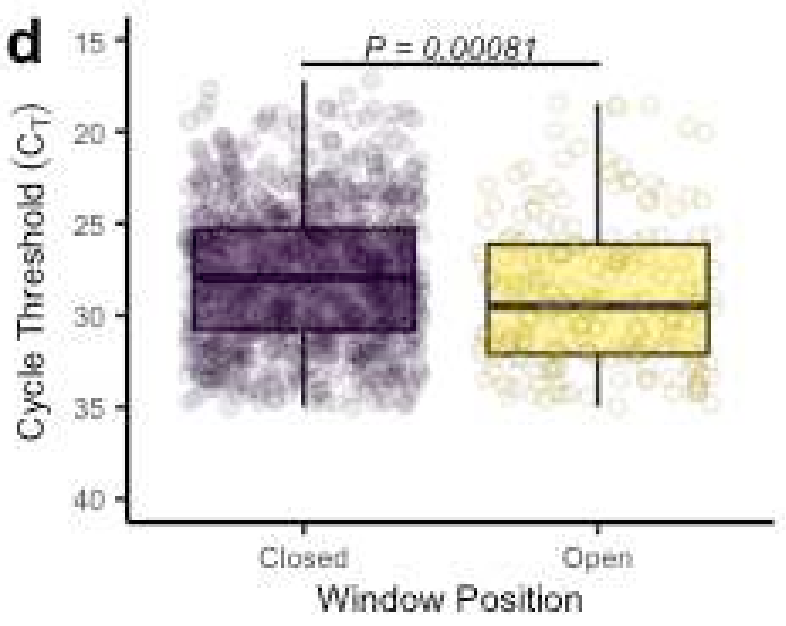

Figure 5. Impact of differential ventilation rates on SARS-CoV-2 RNA identification. (a) Distribution of the calculated air exchanges per hour (ACH) from mechanical exhaust across all isolation rooms occupied by study participants. (b) Relationship between the observed cycle threshold $\left(\mathrm{C}_{\mathrm{T}}\right)$ values and the air changes per hour $(\mathrm{ACH})$ from occupied isolation rooms. The black line indicates fit from a linear model to the raw data and the grey area represents the $\mathbf{9 5 \%}$ confidence interval for that model. Individual points are colored based on the ACH observed in that sample with darker colors representing lower ACH values and lighter colors representing higher ACH values. (c) Relationship between the observed percent positivity from each entry into a subject room and the air changes per hour $(\mathrm{ACH})$ from occupied isolation rooms. The black line indicates fit from a linear model to the raw data and the grey area represents the $95 \%$ confidence interval for that model. Individual points are colored based on the $\mathrm{ACH}$ observed in that sample with darker colors representing lower ACH values and lighter colors representing higher $\mathrm{ACH}$ values. (d) Boxplots of observed cycle threshold (C $\left.\mathrm{C}_{\mathrm{T}}\right)$ values of aerosol samples taken during periods when the window was open for more than $50 \%$ of the sampling period (yellow) or closed for more than $50 \%$ of the sampling period (purple), as recorded during the entry surveys answered by participants.

There are multiple limitations to note in our investigation. Our study population, made up of

students living in the university residence halls, is inherently not a representative sample of the broad

spectrum of individuals that may contract COVID-19. Particularly, our study population is

composed of individuals between the ages of 18 and 24. The age of the individual suffering from 
COVID-19 has been associated with altered levels of detectable SARS-CoV-2 RNA $`$ and viral shedding dynamics may differ from that seen in our investigation. Furthermore, our symptom and window position results are largely based upon the results of self-reported survey data. This survey data may suffer from inconsistencies and misclassification bias, particularly data pertaining to symptom presence and severity ${ }^{80-83}$. Lastly, there is a lack of data demonstrating a presence or absence of SARS-CoV-2 viability throughout the course of the study participants' time in the isolation rooms. SARS-CoV-2 RNA has been demonstrated to remain within patient and environmental samples, even when SARS-CoV-2 viability and infectiousness has ceased ${ }^{8487}$.

Overall, we present a detailed longitudinal analysis of oral, nasal, and environmental viral loads associated with individuals in a quarantine environment. We find that subject samples demonstrate a decrease, but not a ceasing, in overall viral load as their quarantine period progresses. Based upon the self-reported symptoms of study participants, we find that coughing and GI symptoms most strongly correlate with increased environmental contamination, likely through an increase in virus shedding during coughing and bowel activity and movements. Additionally, we demonstrate significant differences in environmental contamination between symptomatic and asymptomatic individuals, as well as between periods of intermittent positive and negative human samples. Lastly, we provide the first real-world experiential evidence for decreased aerosol viral load with increasing mechanical ventilation levels and demonstrate significantly reduced detectable SARS-CoV-2 in study rooms with open windows compared with those with closed windows. These results are directly applicable to those occupying common spaces with an individual known to be positive for COVID19. We demonstrate that even asymptomatic infection with SARS-CoV-2 can yield high levels of environmental contamination. However, we also identified that increasing the total ACH within the space occupied by the COVID-19 positive individual can aid in the reduction of the overall viral 
load present in that environment. Furthermore, we add to the mounting evidence that SARS-CoV-2 is emitted by COVID-19 positive individuals which then disperse into the surrounding space as potentially infectious aerosols which can be monitored through environmental surveillance programs to support awareness and safety. We observe that indoor bioaerosols can be consistently measured with a high-flow bioaerosol sampler and demonstrate utility in biosurveillance and to assess mitigation effectiveness. Ideally, individuals would physically distance themselves from and avoid shared air spaces with a COVID-19 positive individual, ensure the positive individual wears a mask to reduce the quantity of emitted virus, and wear a mask themselves indoors. Ideally, building operators would monitor indoor air for pathogenic bioaerosols and make preparations to increase ventilation when pathogenic bioaerosols are present.

\section{Materials and Methods}

\section{Institutional Approval and Data Availability}

All protocols regarding to the handling of biological materials were reviewed and approved by Advarra Institutional Biosafety Committee (IBC) (Protocol \#PROTO202000132). Advarra IBC is an authorized external IBC for the University of Oregon and is registered with the National Institute of Health (NIH). All protocols relating to human subjects involved in the study were reviewed and approved by the University of Oregon Institutional Review Board (IRB) (Protocol \#12292020).

\section{Subject Recruitment}

University of Oregon COVID-19 protocols require individuals living in the residence halls to move out of their current residence and occupy an isolation dormitory room during the course of their isolation period (14 days). Individuals positive for COVID-19 were identified through the University of Oregon Monitoring and Assessment Program (MAP) ${ }^{88}$. Following transfer to the isolation 
dormitory, individuals were recruited into the program for the duration of their stay at the isolation dormitory or until they wished to be removed from the study.

\section{Subject Questionnaire}

During the first sampling period, study subjects verbally filled out a questionnaire (1st entry questionnaire) that asked participants about their infection timeline, positive test date, age, biological sex, race and ethnicity, recent travel history, lifestyle, medications taken, and symptom onset and severity. Additionally, study subjects verbally completed a followup questionnaire during each subsequent entry into the room to track their symptoms, medications taken, and the status of the study room windows. The symptoms that were tracked included fever, coughing, sneezing, difficulty breathing, fatigue, headache, aching eyes, watering eyes, sore throat, distorted taste, loss of taste, distorted smell, loss of smell, ringing ears, gastrointestinal (GI) symptoms, congestion, and brain fog. Study participants indicated whether or not they were currently experiencing any of the surveyed or other symptoms and the severity on a scale of 1-5, with 5 being the most severe. All survey answers were self-reported by the study participants.

\section{Airflow Monitoring}

The rate of air exhausted from the isolation rooms were determined for each room. The only location which is designed to exhaust air from the rooms is through the exhaust air vent located in the bathroom of each unit or an open window. The room air is supplied from either the building common areas (via a roof-top unit supplying 100\% outside air) or the dormitory room windows.

The velocity of exhausted air from each room was measured by placing a customized adapter with a three inch diameter outlet that rested against the exhaust air grille structural perimeter. A hot wire anemometer (TSI Incorporated, model \#9565) with probe (TSI Incorporated, model \#964) measured the velocity of flow at the center. The measurement was converted to volumetric flow rate 
331 using the equation $V F=\frac{0.9 * \pi * 0.25^{2}}{4} * V$, where $V$ is the measured velocity at the center in feet per

332 minute, 0.25 is the three inch diameter outlet converted to feet, and 0.9 is the conversion factor

333 accounting for peak flow at the center and averaging flow across the area of the hole. The air

334 changes per hour $(\mathrm{ACH})$ flow rate was calculated using the dimensions of the study rooms as

335 described in the architectural plans and the equation $A C H_{F}=\frac{V F * 60}{v}$, where $v$ is the volume of the

336 room in cubic feet, 60 is the minutes in an hour, and $V F$ is the calculated volumetric flow rate.

337 Measurements were taken with (1) the hall door, exterior window and, bathroom door closed, and

338 (2) the hall door closed and the exterior window and bathroom door open.

\section{Sample Collection}

Samples were collected 3-5 times throughout a day with approximately two hours lapsing between subsequent sampling times. At each entry, both a mouth and shallow nasal swab were collected from the study participant. Environmental samples were collected through environmental swabs, passive air settling plates, and active air sampling (Figure 6). Environmental swabs were collected from the participant's cell phone, computer, bathroom floor, and exhaust air grille located within the bathroom. Flocked nylon fiber oropharyngeal swabs (Typenex Medical LLC, Catalog \#SW0202) pre-moistened with DNA/RNA Shield (Zymo Research, Catalog \#R1100) were used to thoroughly swab the sampling location (sampling area $\sim 600 \mathrm{~cm}^{2}$, except for smaller items such as cellphones) for 15-20 seconds and returned to $1 \mathrm{~mL}$ of DNA/RNA Shield. Subject phones and computers were cleaned with bleach wipes following sampling to remove the residue left behind by the DNA/RNA shield. Settled particulates were captured using both components (base and lid) of standard Petri dishes (Corning Scientific). Following the sampling period, both sides of the Petri dish (sampling area $\sim 110 \mathrm{~cm} 2$ ) were swabbed following the protocol described above for environmental swabs. Active air samples were collected using the AerosolSense 2900 sampler (Thermo Scientific, Catalog 

of $200 \mathrm{~L} /$ minute, causing particles to impact onto a collection substrate. Following the sampling period, the collection substrate was transferred to $1 \mathrm{~mL}$ of DNA/RNA Shield using sterilized forceps and transported back to the laboratory. Upon return to the laboratory, the capture media was briefly vortexed, then centrifuged for two minutes at $1,500 \mathrm{x} g$ to collect all liquid from the collection substrate. Following centrifugation, the collection substrate was discarded.

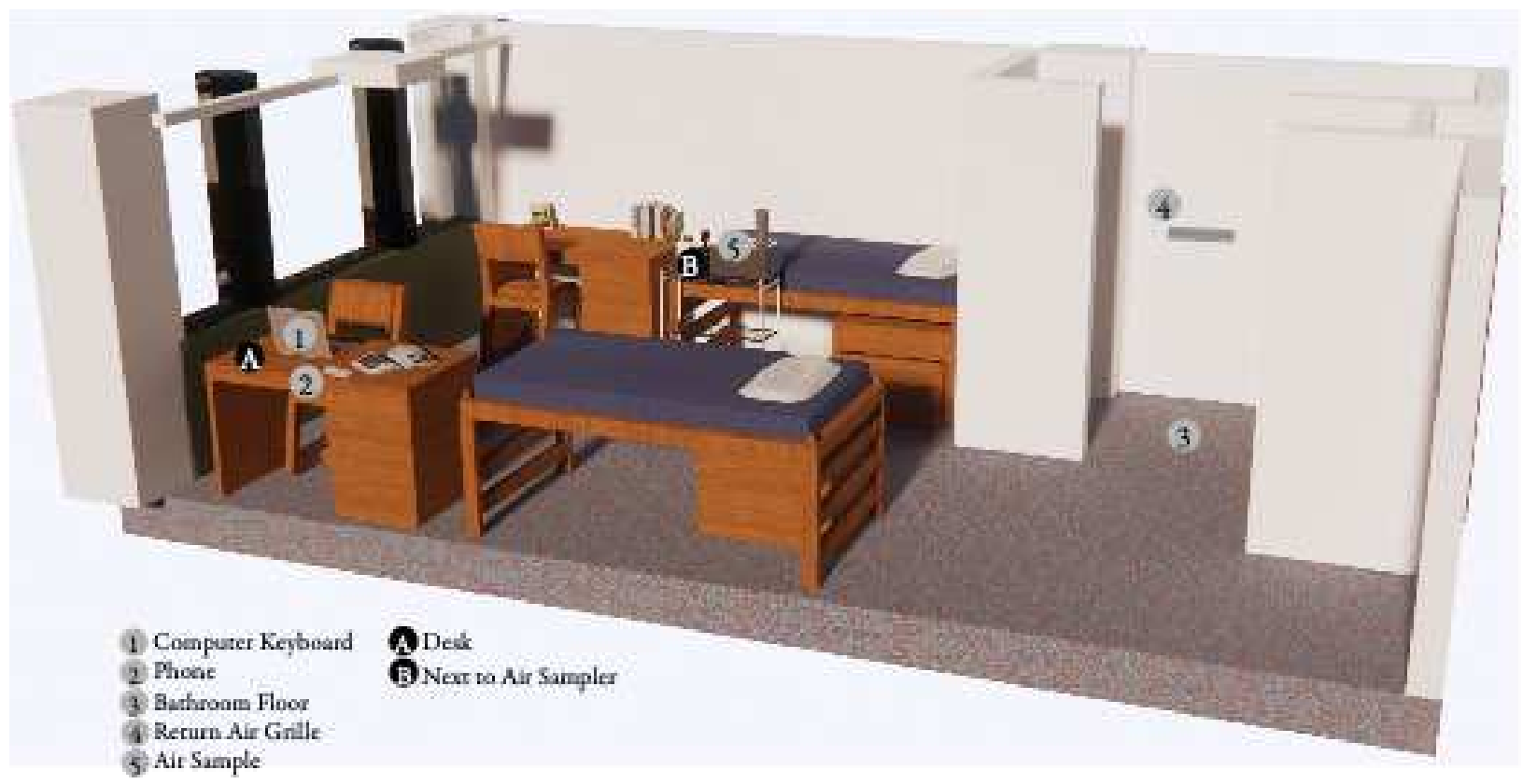

Figure 6. Representative layout of study rooms and sampling locations. Numbers in grey circles represent locations sampled with flocked swabs and letters in black circles represent locations sampled through passive air settling plates. Sampling location 5 represents the active air sample collected with the AerosolSense Sampler

\section{Molecular Analysis}

All protocols were performed in a Purifier Logic + Class II, Type A2 biosafety cabinet (LabConco, Catalog \#302420001). An aliquot of $400 \mu \mathrm{L}$ of each sample was used as the input for RNA extraction using the Quick-DNA/RNA Viral Magbead kit (Zymo Research, Catalog \#R2141) following the manufacturer's protocol. Briefly, $800 \mu \mathrm{L}$ of lysis buffer and $20 \mu \mathrm{L}$ magnetic beads were added to each well, the plate was sealed, and shaken continuously for 10 minutes. Following the ten minute incubation, the supernatant was removed, and the lysates were washed four times 
(1X with MagBead DNA/RNA Wash 1, 1X MagBead with DNA/RNA Wash 2, 2X with 100\%

ethanol). Nucleic acids were eluted into $50 \mu \mathrm{L}$ nuclease-free water and stored at $-80^{\circ} \mathrm{C}$ until downstream analysis. Successful RNA extraction was confirmed in each sample through the addition of a $5 \mu \mathrm{L}$ spike-in of Escherichia coli MS2 bacteriophage into each extraction well. Each extraction plate also contained one extraction control containing nuclease-free water instead of sample.

All samples underwent quantitative reverse-transcription polymerase chain reaction (qRT-PCR) analysis using the TaqPath COVID-19 Combo Kit (Thermo Fisher Scientific, Catalog \#A47814). This quadruplex qRT-PCR reaction targets the spike (S), nucleocapsid $(\mathrm{N})$, and RNA-dependent RNA polymerase (RdRP/ORF1ab) genomic regions. Additionally, the assay also targets the Escherichia coli MS2 bacteriophage as an internal process control. The reaction mixtures included 5 $\mu \mathrm{L}$ TaqPath 1-Step Multiplex Mastermix without ROX (Thermo Fisher Scientific, Catalog \#A28521), $9 \mu \mathrm{L}$ nuclease-free water (Invitrogen, Catalog \#4387936), $1 \mu \mathrm{L}$ COVID-19 Real Time PCR Assay Multiplex Mix (Thermo Fisher Scientific, Catalog \#A47814), and $5 \mu \mathrm{L}$ of template RNA. Thermocycling was performed with the QuantStudio5 (Applied Biosystems) using the following cycling conditions: $25^{\circ} \mathrm{C}$ for 2 minutes, $53^{\circ} \mathrm{C}$ for 10 minutes, $95^{\circ} \mathrm{C}$ for 2 minutes, and 40 cycles of $95^{\circ} \mathrm{C}$ for 3 seconds and $60^{\circ} \mathrm{C}$ for 30 seconds. Samples were considered positive if amplification was observed in two of three genome targets with a cycle threshold (CT) value less than or equal to 35 $\left(\mathrm{C}_{\mathrm{T}}<35\right)^{89}$. Each qRT-PCR plate contained a positive RNA control, a no-template control (nucleasefree water), and three extraction controls. All controls performed as expected.

\section{Statistical Analyses}

Analyses were performed using the statistical programming environment $\mathrm{R}^{90}$. Associations between observed $C_{T}$ values and study subject symptoms were identified through the use of a generalized linear model of the form $y=\beta_{1}\left(x_{1}\right)+\beta_{2}\left(x_{2}\right)+\ldots \beta_{n}\left(x_{n}+E\right)$ where $y$ is the observed $\mathrm{C}_{\mathrm{T}}, \beta_{i}$ 
values are linear regression coefficients for fixed effects $x_{i}$, and $E$ is a vector of errors. Significant changes in $\mathrm{C}_{\mathrm{T}}$ values over time were identified through linear mixed models of the form $y_{i}=X_{i} \beta+$ $Z_{i} u_{i}+\epsilon_{i}^{91,92}$ using a restricted maximum likelihood (REML) approach and including the individual occupying the room as a random effect. Student's t-tests were used to compare differences in observed $C_{T}$ values between sampling groups. Differences were considered significant with $P<0.05$.

\section{Data and Code Availability}

All data and code supporting this study and required to recreate the analyses are deposited in Github at https://github.com/BioBE/UO-COVID-Dorms.

\section{References}

1. National Academies of Sciences, Engineering, and Medicine et al. Microbiomes of the built environment: A research agenda for indoor microbiology, human bealth, and buildings. (National Academies Press, 2017).

2. Horve, P. F. et al. Building upon current knowledge and techniques of indoor microbiology to construct the next era of theory into microorganisms, health, and the built environment. $J$. Expo. Sci. Environ. Epidemiol. 1-17 (2019).

3. Organization, W. H. \& Others. World health organization coronavirus disease (COVID-19) dashboard. (2020).

4. Lu, J. et al. COVID-19 outbreak associated with air conditioning in restaurant, guangzhou, china, 2020. Emerging Infectious Diseases 26, 1628-1631 (2020).

5. Lednicky, J. A. et al. Collection of SARS-CoV-2 virus from the air of a clinic within a university student health care center and analyses of the viral genomic sequence. Aerosol and Air Quality Research vol. 20 1167-1171 (2020).

6. Lednicky, J. A. et al. Viable SARS-CoV-2 in the air of a hospital room with COVID-19 patients. medRxiv (2020).

7. Hamner, L. et al. High SARS-CoV-2 attack rate following exposure at a choir practice skagit county, washington, march 2020. MMWR. Morbidity and Mortality Weekly Report 69, 606-610 (2020).

8. Razzini, K. et al. SARS-CoV-2 RNA detection in the air and on surfaces in the COVID-19 ward of a hospital in milan, italy. Sci. Total Environ. 742, 140540 (2020). 
9. Morawska, L. \& Cao, J. Airborne transmission of SARS-CoV-2: The world should face the reality. Environ. Int. 139, 105730 (2020).

10. Allen, J. G. \& Marr, L. C. Recognizing and controlling airborne transmission of SARS-CoV2 in indoor environments. Indoor Air vol. $30557-558$ (2020).

11. Liu, J., Huang, J. \& Xiang, D. Large SARS-CoV-2 outbreak caused by asymptomatic traveler, china. Emerging Infectious Diseases 26, 2260-2263 (2020).

12. Speake, H. et al. Flight-associated transmission of severe acute respiratory syndrome coronavirus 2 corroborated by whole-genome sequencing. Emerging Infectious Diseases 26, 2872-2880 (2020).

13. Katelaris, A. L. et al. Epidemiologic evidence for airborne transmission of SARS-CoV-2 during church singing, australia, 2020. Emerging Infectious Diseases 27, 1677-1680 (2021).

14. Nissen, K. et al. Long-distance airborne dispersal of SARS-CoV-2 in COVID-19 wards. Sci. Rep. 10, 19589 (2020).

15. Somsen, G. A., Rijn, C. van, Kooij, S., Bem, R. A. \& Bonn, D. Small droplet aerosols in poorly ventilated spaces and SARS-CoV-2 transmission. Lancet Respir Med 8, 658-659 (2020).

16. Dumont-Leblond, N. et al. Positive no-touch surfaces and undetectable SARS-CoV-2 aerosols in long-term care facilities: An attempt to understand the contributing factors and the importance of timing in air sampling campaigns. Am. J. Infect. Control (2021).

17. Correia, G., Rodrigues, L., Gameiro da Silva, M. \& Gonçalves, T. Airborne route and bad use of ventilation systems as non-negligible factors in SARS-CoV-2 transmission. Med. Hypotheses 141, 109781 (2020).

18. Ye, G. et al. Environmental contamination of SARS-CoV-2 in healthcare premises. J. Infect. (2020).

19. Ryu, B.-H. et al. Environmental contamination of SARS-CoV-2 during the COVID-19 outbreak in south korea. Am. J. Infect. Control 48, 875-879 (2020).

20. Ahn, J. Y. et al. Environmental contamination in the isolation rooms of COVID-19 patients with severe pneumonia requiring mechanical ventilation or high-flow oxygen therapy. Journal of Hospital Infection vol. 106 570-576 (2020).

21. Jin, T. et al. SARS-CoV-2 presented in the air of an intensive care unit (ICU). Sustain Cities Soc 65, 102446 (2021).

22. Cheng, V. C.-C. et al. Air and environmental sampling for SARS-CoV-2 around hospitalized patients with coronavirus disease 2019 (COVID-19). Infection Control \& Hospital Epidemiology 41, 1258-1265 (2020).

23. Fernández-de-Mera, I. G. et al. Detection of environmental SARS-CoV-2 RNA in a high prevalence setting in spain. Transbound. Emerg. Dis. 68, 1487-1492 (2021). 
24. Li, Y. H., Fan, Y. Z., Jiang, L. \& Wang, H. B. Aerosol and environmental surface monitoring for SARS-CoV-2 RNA in a designated hospital for severe COVID-19 patients. Epidemiol. Infect. 148, e154 (2020).

25. Escudero, D. et al. SARS-CoV-2 analysis on environmental surfaces collected in an intensive care unit: Keeping ernest shackleton's spirit. Intensive Care Med Exp 8, 68 (2020).

26. Environmental surface and air sampling in the context of the COVID-19 pandemic.

27. Ong, S. W. X. et al. Air, surface environmental, and personal protective equipment contamination by severe acute respiratory syndrome coronavirus 2 (SARS-CoV-2) from a symptomatic patient. $J A M A(2020)$.

28. Coil, D. A. et al. SARS-CoV-2 detection and genomic sequencing from hospital surface samples collected at UC davis. medRxiv (2021).

29. Coil, D. A. et al. SARS-CoV-2 detection and genomic sequencing from hospital surface samples collected at UC Davis. PLOS ONE 16, e0253578 (2021).

30. Borges, J. T., Nakada, L. Y. K., Maniero, M. G. \& Guimarães, J. R. SARS-CoV-2: A systematic review of indoor air sampling for virus detection. Environ. Sci. Pollut. Res. Int. (2021).

31. Horve, P. F. et al. Identification of SARS-CoV-2 RNA in healthcare heating, ventilation, and air conditioning units. Infectious Diseases (except HIV / AIDS) (2020).

32. Hermesch, A. C. et al. Severe acute respiratory syndrome coronavirus 2 (SARS-CoV-2) environmental contamination and childbirth. Obstet. Gynecol. 136, 827-829 (2020).

33. Doremalen, N. van et al. Aerosol and surface stability of SARS-CoV-2 as compared with SARS-CoV-1. N. Engl. J. Med. (2020).

34. Lednicky, J. A. et al. Viable SARS-CoV-2 in the air of a hospital room with COVID-19 patients. Int. J. Infect. Dis. 100, 476-482 (2020).

35. Joukar, F. et al. Persistence of SARS-CoV-2 RNA in the nasopharyngeal, blood, urine, and stool samples of patients with COVID-19: a hospital-based longitudinal study. Virology Journal 18, (2021).

36. Aranha, C., Patel, V., Bhor, V. \& Gogoi, D. Cycle threshold values in RT-PCR to determine dynamics of SARS-CoV-2 viral load: An approach to reduce the isolation period for COVID-19 patients. Journal of Medical Virology (2021) doi:10.1002/jmv.27206.

37. Coil, D. A. et al. SARS-CoV-2 detection and genomic sequencing from hospital surface samples collected at UC Davis. PLOS ONE 16, e0253578 (2021).

38. Zhou, Y., Zeng, Y. \& Chen, C. Presence of SARS-CoV-2 RNA in isolation ward environment 28 days after exposure. International Journal of Infectious Diseases 97, 258-259 (2020). 
39. Lavezzo, E. et al. Suppression of a SARS-CoV-2 outbreak in the Italian municipality of Vo'. Nature 584, 425-429 (2020).

40. Finelli, C. \& Parisi, S. The clinical impact of COVID-19 epidemic in the hematologic setting. Advances in Biological Regulation 77, 100742 (2020).

41. Arons, M. M. et al. Presymptomatic SARS-CoV-2 Infections and Transmission in a Skilled Nursing Facility. New England Journal of Medicine 382, 2081-2090 (2020).

42. Zhou, R. et al. Viral dynamics in asymptomatic patients with COVID-19. International Journal of Infectious Diseases 96, 288-290 (2020).

43. Wei, W. E. et al. Presymptomatic transmission of SARS-CoV-2 singapore, january 23march 16, 2020. MMWR. Morbidity and Mortality Weekly Report 69, 411-415 (2020).

44. Bernal, J. L. et al. Transmission dynamics of COVID-19 in household and community settings in the united kingdom. (2020).

45. Decker, A. et al. Prolonged SARS-CoV-2 shedding and mild course of COVID-19 in a patient after recent heart transplantation. American Journal of Transplantation 20, 3239-3245 (2020).

46. Folgueira, M. D., Luczkowiak, J., Lasala, F., Pérez-Rivilla, A. \& Delgado, R. Persistent SARS-CoV-2 replication in severe COVID-19. (2020).

47. van Kampen, J. J. A. et al. Shedding of infectious virus in hospitalized patients with coronavirus disease-2019 (COVID-19): Duration and key determinants. (2020).

48. Riediker, M. \& Tsai, D.-H. Estimation of Viral Aerosol Emissions From Simulated Individuals With Asymptomatic to Moderate Coronavirus Disease 2019. JAMA Network Open 3, e2013807 (2020).

49. Wang, Y., Xu, G. \& Huang, Y.-W. Modeling the load of SARS-CoV-2 virus in human expelled particles during coughing and speaking. PLOS ONE 15, e0241539 (2020).

50. Riediker, M. \& Tsai, D.-H. Estimation of Viral Aerosol Emissions From Simulated Individuals With Asymptomatic to Moderate Coronavirus Disease 2019. JAMA Network Open 3, e2013807 (2020).

51. Peccia, J. et al. Measurement of SARS-CoV-2 RNA in wastewater tracks community infection dynamics. Nature Biotecbnology 38, 1164-1167 (2020).

52. Parasa, S. et al. Prevalence of Gastrointestinal Symptoms and Fecal Viral Shedding in Patients With Coronavirus Disease 2019. JAMA Network Open 3, e2011335 (2020).

53. V'kovski, P. et al. Disparate temperature-dependent virushost dynamics for SARS-CoV-2 and SARS-CoV in the human respiratory epithelium. PLOS Biology 19, e3001158 (2021).

54. Aljishi, J. M. \& Al-Tawfiq, J. A. Intermittent viral shedding in respiratory samples of patients with SARS-CoV-2: observational analysis with infection control implications. Joumal of Hospital Infection 107, 98-100 (2021). 
55. Li, N., Wang, X. \& Lv, T. Prolonged SARS-CoV-2 RNA shedding: Not a rare phenomenon. Journal of Medical Virology 92, 2286-2287 (2020).

56. Liu, W.-D. et al. Prolonged virus shedding even after seroconversion in a patient with COVID-19. Journal of Infection 81, 318-356 (2020).

57. Lau, M. S. Y. et al. Characterizing superspreading events and age-specific infectiousness of SARS-CoV-2 transmission in Georgia, USA. Proceedings of the National Academy of Sciences 117, 22430-22435 (2020).

58. Parhizkar, H., Van Den Wymelenberg, K., Haas, C. \& Corsi, R. A quantitative risk estimation platform for indoor aerosol transmission of COVID-19. (2021).

59. Majra, D., Benson, J., Pitts, J. \& Stebbing, J. SARS-CoV-2 (COVID-19) superspreader events. J. Infect. 82, 36-40 (2021).

60. Hamner, L. High SARS-CoV-2 attack rate following exposure at a choir practice-skagit county, washington, march 2020. MMWR Morb. Mortal. Wkly. Rep. 69, (2020).

61. Jianyun Lu et al. COVID-19 outbreak associated with air conditioning in restaurant, guangzhou, china, 2020. Emerging Infectious Disease journal 26, (2020).

62. Speake, H. et al. Flight-associated transmission of severe acute respiratory syndrome coronavirus 2 corroborated by whole-genome sequencing. Emerging Infectious Diseases 26, 2872-2880 (2020).

63. Katelaris, A. L. et al. Epidemiologic evidence for airborne transmission of SARS-CoV-2 during church singing, australia, 2020. Emerging Infectious Diseases 27, 1677-1680 (2021).

64. Thanh, H. N. et al. Outbreak investigation for COVID-19 in northern Vietnam. The Lancet Infectious Diseases 20, 535-536 (2020).

65. Escandón, K. et al. COVID-19 false dichotomies and a comprehensive review of the evidence regarding public health, COVID-19 symptomatology, SARS-CoV-2 transmission, mask wearing, and reinfection. BMC Infectious Diseases 21, (2021).

66. The American Society of Heating, Refrigerating and Air Condition Engineers, Inc. (ASHRAE). Ventilation of health care facilities (ANSI/ ASHRAE/ASHE standard 170-2017). (2017).

67. Allen, J. G. \& Ibrahim, A. M. Indoor Air Changes and Potential Implications for SARSCoV-2 Transmission. JAMA 325, 2112 (2021).

68. Chia, P. Y. et al. Detection of air and surface contamination by SARS-CoV-2 in hospital rooms of infected patients. Nature Communications 11, (2020).

69. Dietz, L. et al. 2019 Novel Coronavirus (COVID-19) Pandemic: Built Environment Considerations To Reduce Transmission. mSystems 5, (2020).

70. Klompas, M., Baker, M. A. \& Rhee, C. Airborne Transmission of SARS-CoV-2. JAMA 324, 441 (2020). 
71. Howard-Reed, C., Wallace, L. A. \& Ott, W. R. The Effect of Opening Windows on Air Change Rates in Two Homes. Journal of the Air \& Waste Management Association 52, 147-159 (2002).

72. Qian, H. et al. Natural ventilation for reducing airborne infection in hospitals. Building and Environment 45, 559-565 (2010).

73. Escombe, A. R. et al. Natural Ventilation for the Prevention of Airborne Contagion. PLoS Medicine 4, e68 (2007).

74. Morawska, L. et al. How can airborne transmission of COVID-19 indoors be minimised? Environment International 142, 105832 (2020).

75. Nembhard, M. D., Burton, D. J. \& Cohen, J. M. Ventilation use in nonmedical settings during COVID-19: Cleaning protocol, maintenance, and recommendations. Toxicology and Industrial Health 36, 644-653 (2020).

76. Mathai, V., Das, A., Bailey, J. A. \& Breuer, K. Airflows inside passenger cars and implications for airborne disease transmission. Science Advances 7, eabe0166 (2020).

77. Bhagat, R. K., Davies Wykes, M. S., Dalziel, S. B. \& Linden, P. F. Effects of ventilation on the indoor spread of COVID-19. Journal of Fluid Mechanics 903, (2020).

78. Jarvis, M. C. Aerosol transmission of SARS-CoV-2: Physical principles and implications. Frontiers in Public Health 8, (2020).

79. Zhou, C. et al. Impact of age on duration of viral RNA shedding in patients with COVID-19. Aging (2020) doi:10.18632/aging.104114.

80. Daniali, H. \& Flaten, M. A. What psychological factors make individuals believe they are infected by coronavirus 2019? Frontiers in Psychology 12, (2021).

81. Kluytmans-van den Bergh, M. F. Q. et al. Prevalence and Clinical Presentation of Health Care Workers With Symptoms of Coronavirus Disease 2019 in 2 Dutch Hospitals During an Early Phase of the Pandemic. JAMA Network Open 3, e209673 (2020).

82. Nomura, S. et al. An assessment of self-reported COVID-19 related symptoms of 227,898 users of a social networking service in Japan: Has the regional risk changed after the declaration of the state of emergency? The Lancet Regional Health - Western Pacific 1, 100011 (2020).

83. Merckelbach, H., Dandachi-FitzGerald, B., van Helvoort, D., Jelicic, M. \& Otgaar, H. When Patients Overreport Symptoms: More Than Just Malingering. Current Directions in Psychological Science 28, 321-326 (2019).

84. Zhang, Y. et al. Prevalence and Persistent Shedding of Fecal SARS-CoV-2 RNA in Patients With COVID-19 Infection: A Systematic Review and Meta-analysis. Clinical and Translational Gastroenterology 12, e00343 (2021).

85. Rawlings, S. A. et al. No Evidence of SARS-CoV-2 Seminal Shedding Despite SARS-CoV-2 Persistence in the Upper Respiratory Tract. Open Forum Infectious Diseases 7, (2020). 
86. Yang, J.-R. et al. Persistent viral RNA positivity during the recovery period of a patient with SARS-CoV-2 infection. Journal of Medical Virology 92, 1681-1683 (2020).

87. Kang, H., Wang, Y., Tong, Z. \& Liu, X. Retest positive for SARS-CoV-2 RNA of "recovered" patients with COVID-19: Persistence, sampling issues, or re-infection? Journal of Medical Virology 92, 2263-2265 (2020).

88. University of Oregon. Monitoring and assessment program (MAP).

89. TaqPath COVID-19 combo kit - instructions for use.

90. Team, R. C. \& Others. R: A language and environment for statistical computing. (2013).

91. Laird, N. M. \& Ware, J. H. Random-effects models for longitudinal data. Biometrics 38, 963974 (1982).

92. Raudenbush, S. W. \& Bryk, A. S. Hierarchical linear models: Applications and data analysis methods. (SAGE, 2002).

\section{Acknowledgements}

The authors would like to thank Chuck Williams and Tony Schaffer, University of Oregon, for their aid in forming a relationship with Thermo Fisher Scientific. The authors would like to thank countless staff members from the University of Oregon. The authors would like to acknowledge the tireless team at BioBE for all of their help, including Surbhi Nahata, Kate Qi, Jackson Mestler, Dan Richards, Kathrine Tush, Liliya Zagorski, and Ellie Thacker. Most importantly, we would like to extend a special thanks to the study participants who welcomed us during a very stressful event in their lives.

\section{Author Contributions}

KGVDW performed funding acquisition and managed the investigation team. PFH, LGD, and KGVDW conceived of project scope and methodology. KGVDW and LGD enrolled and consented study participants. GB and PFH performed data curation and initial data exploration. PFH developed final analysis scripts, performed final analysis, and created visualizations. PFH, 
630 analyses. PFH developed the original manuscript with direction and input from KGVDW. LGD,

631 GB, GM, AOM, DN, VM, LB, HP, and KGVDW provided manuscript revisions and edits on

632 subsequent manuscript drafts.

\section{Competing Interests Statement}

634 KGVDW has a company called Duktile through which he provides healthy building consulting,

635 including consulting related to viral pathogens, and he serves as a scientific advisor to EnviralTech, a

636 company that conducts viral surface surveillance, including in senior care facilities. No other authors

637 have any competing interests to declare. 